\title{
PUERTO GAITÁN: TRANSFORMACIÓN ADMINISTRATIVA, 2000-2011 ${ }^{1}$
}

\author{
Wilson Ladino Orjuela ${ }^{1}$ \\ Abel Abella Beltran ${ }^{2}$ \\ Fidel Rodriguez Urueña ${ }^{3}$
}

\section{RESUMEN}

Se presentan a continuación los resultados de la investigación realizada durante tres meses en el año 2012 y cuatro meses en el año 2013, desde la Territorial Once de la ESAP, sobre el municipio de Puerto Gaitán, en el Departamento del Meta.

Se buscó establecer la transformación a que se ha visto obligada la institucionalidad del municipio a raíz de la producción petrolera que se empezó a finales del siglo pasado y comienzos del siglo XXI, así como a la súbita llegada de migrantes de diferentes lugares del país.

El estudio describe lo ocurrido con el proceso de planeación municipal, el Esquema de Ordenamiento Territorial, las transformaciones de la estructura administrativa, los cambios en los patrones de vinculación del personal que labora en la municipalidad, los cambios que se observan en el presupuesto municipal, las tendencias que se perciben en los ingresos y gastos, las tendencias que se pueden describir en los procesos electorales celebrados durante el decenio (2000-2011), y la composición del Concejo Municipal.

\section{PALABRAS CLAVES}

Administración pública, planeación municipal, presupuesto municipal, ordenamiento territorial, estructura administrativa.

\begin{abstract}
This article shows the results of a research study made for three months in 2012 and four months in 2013 at the Territorial Once of the ESAP about the municipality Puerto Gaitan, in the department El Meta.

We tried to establish the transformation forced on the institutions of the municipality due to the production of petroleum, which started at the end of the last century, and beginnings of the XXI century, along with the sudden arrival of migrants from different places in the country.

This study shows what took place in the process of municipal planning, the scheme of spatial order, the transformations of administrative structure, the changes in the patterns of linking the staff that works in the municipality, the changes that are observed in the municipal budget, the tendencies that are perceived in the incomes and expenses, the tendencies that are perceived in the electoral processes celebrated during the decade (2000-2011) and the composition of the municipal council.
\end{abstract}

\section{KEYWORDS}

Public and local administration, local planning, local administration.

Depositado en agosto 15 de 2014, aprobado en octubre 31 de 2014.

\footnotetext{
1 Sociólogo. Máster en Sociología. Candidato a doctor en Gobierno y Administración Pública IOG-Universidad Complutense de Madrid. Profesor asociado Escuela Superior de Administración Pública. DEA en Gobierno y Administración Pública. E-mail: wilson.ladino@esap. edu.co

2 Administrador Público de la Escuela Superior de Administración Pública, Especialista en Proyectos de Desarrollo de la ESAP. Investigador junior. E-mail: abelantonio98@gmail.com

3 Administrador Público de la Escuela Superior de Administración Pública. E-mail: rafico691@gmail.com

En el presente artículo participaron como colaboradores Yamile Rodríguez U, e-mail: sandrayami14@gmail.com; y, Juan David Alarcón, alarcon506@esap.gov.co, administradores públicos de la ESAP.
} 


\section{INTRODUCCIÓN}

En este documento se consigna una aproximación a las transformaciones que tuvo el municipio de Puerto Gaitán entre los años 2000-2011, determinados por los procesos de sísmica, exploración y producción de petróleo en su jurisdicción de $17.490 \mathrm{kmts} 2$.

La administración municipal de Puerto Gaitán era, en el año 2000, similar a más de 900 administraciones locales de sexta categoría que existían en Colombia: una pequeña nómina de funcionarios, con baja profesionalización de sus directivos, simplificada al mínimo en su nivel central, con nivel descentralizado casi inexistente o con apenas la empresas de servicios públicos para el cobro del servicio de energía eléctrica, con el mínimo de concejales que permite la Ley, quienes son, en su mayoría son líderes urbanos o veredales y desconocían la complejidad de la administración municipal, los procedimientos y trámites que se deben adelantar para la consecución de soluciones a los problemas más sentidos en las comunidades urbanas y rurales.

Se indagó por el sustento conceptual que orientó cada una de estas reestructuraciones, la creación de nuevas oficinas para atender las competencias y funciones asignadas por la Ley, respondiendo siempre a los principio de saneamiento fiscal determinados por la Ley 617.

Se dedica un apartado a la planeación local, la experiencia de la administración, la participación de asesores, la conceptualización, la comprensión de la situación local en cada momento y la participación de la comunidad, a través de sus líderes, en cada uno de los períodos de gobierno. También se hace una descripción de los componentes del Esquema de Ordenamiento Territorial y su significado para la administración municipal. No se tiene conocimiento de rendiciones de cuentas sino luego de 2011. Otra sección muestra las estructuras administrativas del municipio a partir del año 2000 y cómo terminó en 2011, luego de dos reestructuraciones.

Se presenta la información sobre nóminas de funcionarios, en sus diferentes condiciones y de contratistas, vinculados a la administración local en el período estudiado. Se expone así, la tendencia que ha seguido la carrera administrativa y la contratación de personal temporal en la administración.

Se incluye en la exposición la descripción y el análisis de los ingresos y gastos del municipio a lo largo del período estudiado. Un siguiente apartado muestra los resultados electorales a lo largo del primer decenio en el Municipio de Puerto Gaitán y las tendencias que se pueden resaltar. Se señalan algunos rasgos del órgano coadministrador local, la gestión de los concejales, medida por los Acuerdos municipales. Se consignan las conclusiones del trabajo.

\section{ASPECTOS TEÓRICOS}

La aproximación a la transformación vivida por la municipalidad de Puerto Gaitán tiene una perspectiva teórica que se puede definir como de la Nueva Gestión Pública, para lo cual la exposición del profesor Luis F. Aguilar es pertinente.

Las transformaciones administrativas vividas en el Municipio deben ser estudiadas en el marco de la descentralización política, administrativa y financiera establecida por la Asamblea Nacional Constituyente y determinada en la Constitución de 1991.

El concepto de Gobernanza es central a la hora de comprender los procesos del gobierno nacional y sub nacional colombiano a partir de 1991 . Se puede decir sin dudas que la nueva Constitución Política colombiana estableció el mandato de gobernar en "modo" de gobernanza, es decir de formular, ejecutar y evaluar la política pública (decisiones gubernamentales) con la participación de sectores organizados de la sociedad civil sobre la que tienen efecto dichas políticas públicas.

\subsection{NUEVA GESTIÓN PÚBLICA (NGP)}

En el libro de Luis F Aguilar "Gobernanza y Gestión Pública", se presentan una serie de reflexiones sobre lo que ha sido la vieja gobernanza y lo que debe ser la nueva gobernanza, también toca aspectos de manera expositiva 
sobre la gestión estratégica en el ámbito administrativo público. Señala los inconvenientes que presentan estos modelos de administrar y la necesidad de comprometer a la sociedad en los asuntos del gobierno.

La Administración Pública, en su evolución y transformación, depende de la acción del gobierno, prueba de ello fue el siglo XX cuyo eje como Estado social fue un enfoque desarrollistas con limitaciones en su naturaleza republicana y democrática y las prácticas de hacienda pública.

Sostiene Aguilar, que para entender la evolución de la AP, se debe remitir a las dos tendencias que han planteado teóricos y expertos. Una de ellas es la naturaleza de la AP y la otra es la capacidad administrativa, también conocidas con el nombre de "pública y gerencial", estas tienen puntos de convergencia y complementariedad.

La primera tendencia se relaciona con la lucha de los pueblos por sus derechos. El resultado son ciudadanos y sociedades que ahora dan seguimiento a la actuación de los poderes públicos, además se pronuncian frente a los asuntos públicos que tocan con el interés de su supervivencia en cuanto a la calidad de vida y que luchan para que se le de participación en la agenda de gobierno y en la elaboración de políticas públicas.

La segunda tendencia se relaciona con la reconstrucción de la capacidad administrativa y gerencial de la AP. Su enfoque son las medidas de ajuste y equilibrio hacendario, necesarias para mantener la salud de las finanzas estatales, asegurar la viabilidad del mismo Estado y cumplir con su función social.

Manifiesta Aguilar que estas deben complementarse con la administración y dirección de la sociedad y que no deben estar separadas. La situación es la interpretación y aplicación que le dan los gobiernos en el estilo de administrar y dirigir.

En segundo lugar, la estructura de la nueva gobernación y/o gobernanza debe estar articulada a los métodos y tecnologías que plantea la NGP. Si bien es cierto que se tiene una estructura y una guía para aplicar los métodos y técnicas, también se debe visionar que hay una sociedad que puede realizar importantes aportes al gobierno, no es solo administrar sino que hay una sociedad que se debe dirigir mediante propuestas participativas.

En tercer lugar, propone que este concepto debe ser aceptado por el gobierno, pues los supuestos y componentes teóricos representan un nuevo modelo de gobernar. Este es un cambio de idea del gobierno y de gobernar, es el paso de un centralismo a un sistema de gobierno y el paso de una estructura jerárquica a una más asociativa y coordinada.

Aguilar plantea que el gobierno es insuficiente para dirigir a las sociedades contemporáneas. La solución no es achicar el Estado. Plantea además que la NGP se ha dedicado a administrar más no a dirigir a la sociedad, dejando de lado a los actores que pueden ser parte de la solución de los problemas.

En síntesis, el autor quiere demostrar en su análisis, que los modelos de administración en su momento fueron eficientes, pero que la sociedad contemporánea es más exigente $\mathrm{y}$, la propuesta de la NGP para administrar no es suficiente. El gobierno debe darle participación a la sociedad para que con sus recursos y propuestas puedan ser parte de la solución y desarrollo del territorio.

Para conocer el nacimiento de la gestión estratégica en la política no se debe mirar la estrategia de los antiguos militares, ya que el Estado no puede basarse en la premisa de eliminar al "enemigo" u opositor. Aunque parezca raro, los inicios se deben buscar en el desarrollo conceptual de la gestión estratégica privada. Debido a que esta última, por las reglas de juego, no busca eliminar "literalmente" a sus competidores la empresa busca lograr y mantener una ventaja competitiva sobre ellos.

Existen dos enfoques en la elaboración de estrategias que se pueden utilizar en el sector público:

Enfoque bélico/competitivo: este enfoque es muy utilizado por los ejércitos y empresas, es- 
tos consideras a los demás actores como rivales, existe una relación clara de competencia, entonces consiste en la derrota del adversario, buscando una ventaja competitiva. Por lo tanto, el diseño de la estrategia se basa en ganarle al adversario.

Enfoque excelencia/liderazgo: busca la mejora de la capacidad de respuesta de la organización frente a la demanda de cliente o usuario. En este enfoque la competencia se da con uno mismo, la organización busca superarse y brindar un producto de mejor calidad.

De este último enfoque viene la noción de gestión de la calidad, como mecanismo para brindar un mejor servicio tanto al cliente interno como al externo.

\section{PROCEDIMIENTO}

Es una investigación descriptiva que busca identificar elementos de la nueva gestión pública en su proceso de transformación y si se pueden determinar "saltos" o cambios progresivos en las nuevas formas de organización que presenta la administración local.

El trabajo de investigación se comenzó en Septiembre del año 2012, con recopilación de información disponible en diferentes fuentes: el municipio, el periódico local, la contraloría departamental, el DANE, el Poder Judicial, el Concejo Municipal, entrevistas a líderes locales, indígenas, entrevistas a personal directivo de las empresas asociadas de Ecopetrol dedicadas a la producción petrolera.

En el año 2013, continuó a partir del mes de Agosto y hasta Diciembre. Se avanzó en recolección de información en diversas fuentes locales. Se adelantaron tres salidas de campo al casco urbano del municipio de Puerto Gaitán y una a la ciudad de Bogotá para visitar universidades y el Archivo General de la Nación, indagando por información sobre el municipio, en el período de estudio.

Esta etapa permitió consolidar información financiera, de estructuras administrativas, de funcionariados y contratistas municipales en los años del estudio y se dio comienzo al análisis de la información colectada y a la redacción del informe final.

No obstante los problemas de seguridad, se pudo adelantar el trabajo de obtención de información sin inconvenientes. Los funcionarios de la administración municipal prestaron su colaboración haciendo entrega de la información requerida y atendiendo de entrevistas semi estructuradas preparadas por el grupo de investigación.

\section{HALLAZGOS}

En los siguientes apartados se presentarán los principales hallazgos realizados por el grupo de investigación.

\subsection{PLANEACIÓN 2000-2011}

Se obtuvieron los planes de desarrollo municipal de los períodos 1998-2000, 2001-2003, 2004-2007, 2008-2011, (Puerto Gaitán, 1998; Puerto Gaitán, 2000, Puerto Gaitán, 2004, Puerto Gaitán, 2008) lo que ha permitido estudiar con seguridad las principales ideas que se elaboraron en la etapa pre y post petrolera.

La administración municipal contó con el apoyo de expertos externos que le permitieron consolidar documentos que integraban los elementos exigidos por la Ley de Planeación expedida por el Congreso en 1994. El Alcalde Mauro Cristóbal Niño, decidió contratar a un equipo de asesores externos, egresados de la ESAP. En la preparación del plan trabajaron los funcionarios del equipo municipal, el Consejo Municipal de Planeación y los mismos concejales. E1 plan tenía el lema "Progreso y Desarrollo con Honestidad”. (Puerto Gaitán, 1998).

El Alcalde Municipal Oscar Bolaños Cubillos, desempeña su primera administración en Puerto Gaitán. En marzo de 2001, con la dirección de un asesor municipal y el equipo de la administración local, se entrega el documento compuesto por tres capítulos que incluyen "definiciones generales, principios y políticas fundamentales, marco jurídico del plan, desarrollo metodológico, aspectos generales del municipio, Misión, 
visión, diagnóstico, objetivos, metas, estrategias, plan operativo, plan de inversiones, plan plurianual, diagnóstico sectorial por dimensiones, plan financiero y el capítulo tercero la instrumentación del plan: planes parciales, ajuste fiscal, banco de proyectos y fichas de gestión. (Puerto Gaitán, 2001)

El señor Alcalde Jaime Apolonio Ballesteros Cantillo, formula el plan de desarrollo "Con nuestra gente gobernamos", el cual tuvo dos ajustes, el primero mediante Acuerdo No. 015 de octubre de 2004 y luego mediante Acuerdo No. 004 de 15 de septiembre de 2005, teniendo en cuenta que la Contraloría Departamental del Meta no había fenecido el presupuesto municipal. (Puerto Gaitán, 2005)

El Alcalde municipal, por segunda vez, Oscar Eurín Bolaños Cubillos, presenta el documento "Capacidad para el Desarrollo", el cual fue aprobado siguiendo todos los trámites establecidos en la Ley. (Puerto Gaitán, 2008).

El plan elaborado con la asesoría de varios profesionales externos, se compone de: tres títulos y varios anexos. El primer título se refiere al componente estratégico, el segundo al diagnóstico, el tercero a los ejes estratégicos de inversión, los cuales son cuatro y el plan plurianual de inversiones. Entre los proyectos prioritarios se señalan: "Para este Plan se consideran proyectos prioritarios los correspondientes a los siguientes programas: Programa Agua Potable y Permanente para todos, Manejo técnico y sanitario de aguas residuales y lluvias, Eliminación Técnica y Sanitaria de Residuos Sólidos, Suministro de Energía eléctrica, Gas Natural para Todos, Puerto Gaitán Territorio de Propietarios, Aseguramiento en $\mathrm{Sa}-$ lud, Prestación y Desarrollo de Servicios en Salud, Salud Pública, Promoción Social, Aumento de la cobertura educativa, Educación con calidad, Construcción y mejoramiento de la, infraestructura educativa, educación no formal para el trabajo y la convivencia, cultura con identidad y visión universal, atención prioritaria a la niñez, la infancia y la adolescencia, impulso al etnodesarrollo, Economía Campesina para desarrollar nuestra comunidad rural, Cadenas productivas para fortalecer la economía campesina, Plan sectorial turístico de Puerto Gaitán, Vías para la competitividad, capacidad para preservar el entorno de hoy y del mañana, Implementación de instrumentos para mejorar la gestión, capacidad para el fortalecimiento fiscal, Equipamiento para el desarrollo de Puerto Gaitán y Paz y Convivencia ciudadana" (p. 162-163).

Entre 1998 y 2005 no se advierte, en los ejercicios de planeación, el impacto y transformaciones que generarán en la administración local las nuevas condiciones de la producción petrolera y la transferencia de recursos financieros en el volumen y velocidad con la que ocurrieron a partir de 2005.

El plan de desarrollo del período 2004-2007 tuvo que ser modificado en dos oportunidades, en septiembre de 2004 y en octubre de 2005 pues la Contraloría Departamental del Meta no feneció el presupuesto de 2004, por no haberse dejado prevista la inversión adicional que permitía la transferencia de regalías.

Esta falta de información en la municipalidad o asimetría de conocimiento que se plantea, mostraría que los principios de complementariedad o subsidiariedad o de coordinación y concurrencia no se cumplen a cabalidad.

En los diagnósticos de todos los planes de desarrollo no existe referencia a los temas de seguridad o de orden público en el Municipio, no obstante ser conocida la presencia de las FARC y de las Autodefensas y de Víctor Carranza en la jurisdicción municipal (Cepeda \& Giraldo, 2012) (Velásquez, y otros, 2009); (Romero, 2011); (González, Gutiérrez, Nieto, Aponte, \& Rodríguez, 2012), (Camargo, 2004).

Las comunidades indígenas, en número superior, para el año 2000 a la población mestiza tradicional y urbana residente en la municipalidad, si bien aparecían como objeto de preocupación y se manifiesta en los documentos la intención de atenderlas, quedaron por fuera de la acción cotidiana de la municipalidad. No hay planes de vida formulados en el período estudiado. (Puerto Gaitán, 1998, 2000, 2004)

En el diagnóstico del plan de desarrollo formulado en 1998, se deja constancia de que la 
"Participación ciudadana es muy pobre o casi nula y el desarrollo comunitario muy deficiente, son muy pocas las personas que hacen parte de las juntas de acción comunal, lo mismo que del comité de desarrollo y control social de los servicios públicos domiciliarios que allí funciona" (Puerto Gaitán, 1998), descripción que se repite en los siguientes diagnósticos de 2000, 2004, y 2008.

\subsection{COORDINACIÓN CON EL DEPAR- TAMENTO}

La coordinación entre el gobierno municipal y el gobierno departamental a lo largo del período ha sido "difícil". Fue mínima la coordinación entre estos dos niveles del ejecutivo si se retoma la observación que en el año 2005 hizo la contraloría departamental del Meta y que obligó al Municipio a ajustar y "armonizar" el plan de desarrollo local con el plan de desarrollo departamental y el nacional.

En el documento de rendición de cuentas del año 2013 también se expresa que "ante la imposibilidad de intervenir directamente en la educación preescolar, básica y media con estrategias de calidad como el nombramiento de docentes o la ampliación de programas curriculares, se implementaron estrategias de trabajo social como el Plan de Alimentación Escolar y el Programa de Transporte Escolar." (Puerto Gaitán, 2013)

\subsection{COORDINACIÓN CON LA NACIÓN}

Las relaciones y la coordinación entre el nivel Gobierno Municipal y la Nación no se produjeron de manera fluida si se observan los planes de desarrollo y en ellos no se encuentran datos sobre las perspectivas petroleras que se avecinaban en el municipio. El Ministerio de Minas y Ecopetrol, eran conocedores de las proyecciones, a partir de la información que le aportaba la empresa Asociada, en la zona de Rubiales, la cual ya desde 1998 venía adelantando procesos de exploración y perforación.

Los conflictos aparecidos en los últimos años en las zonas de producción (Rubiales) dejan evidente la importancia de la coordinación en- tre niveles de Gobierno. En este sentido el señor Gobernador del Meta en una entrevista que le hace un periodista nacional, manifiesta la necesidad y la importancia, en el caso de Puerto Gaitán, de establecer una concertación entre "el nivel municipal, el departamental, el nacional y la empresa privada" (Especiales Pirry, 2013)

\section{ESQUEMA DE ORDENAMIENTO TE- RRITORIAL, EOT.}

El municipio de Puerto Gaitán aprobó en el mes de diciembre en el año 1999 el Acuerdo No. 056 mediante el cual se expide el Esquema de Ordenamiento Territorial, EOT, el cual no contó con el visto bueno de la Corporación Ambiental que ejercía el control en la jurisdicción municipal, Corporinoquia.

En el mes de junio de 2000 se aprueba el Acuerdo No. 031 de 26 de junio, esta vez con el visto bueno de Corporinoquia. En 2004 se aprueba la primera modificación a las regulaciones de corto y mediano plazo establecidas en el EOT mediante el Acuerdo No. 007. En el año 2009 se producen dos modificaciones, la primera mediante Acuerdo No. 012 de abril y la segunda mediante Acuerdo No. 017 de agosto, de acuerdo con lo establecido en la Ley 388.

Los ciudadanos, acostumbrados a "fundarse" o "asentarse" en cualquier lugar del territorio, a "desmontar" cualquier lugar, a "rozar" y "quemar" cualquier área considerada conveniente para sus fines domésticos, ahora deben consultar a la administración local sobre lo que se puede hacer y lo que está prohibido, según las regulaciones aprobadas en el Esquema de Ordenamiento Territorial, EOT. El municipio debió recurrir al principio de la coordinación con otras instituciones como el INGEOMINAS, IGAC o el IDEAM para contar con las herramientas técnicas.

En los primeros años del nuevo milenio la administración municipal, se ha visto obligada a incorporar nuevas nociones sobre ocupación del suelo urbano y rural. Pero lo más importante, desde el punto de vista de la gestión municipal, es construir la capacidad de actuar sobre los particulares para que orienten su conducta a 
Mapa 4: Usos del Suelo Urbano.

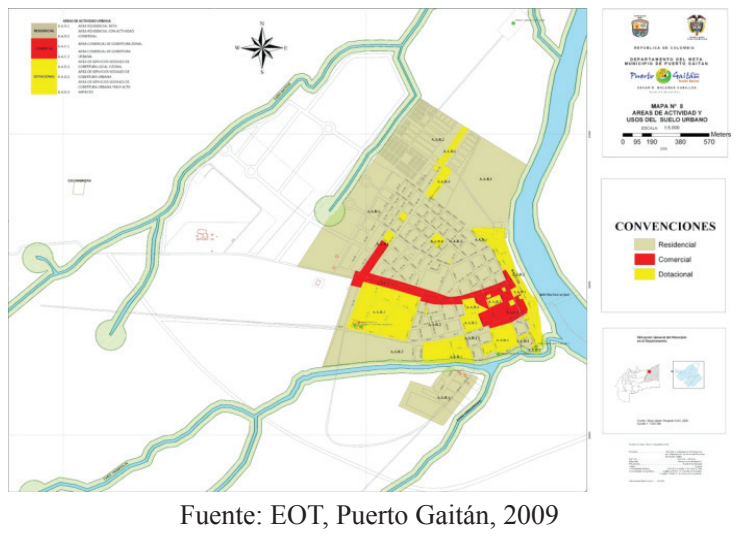

partir de las regulaciones existentes, las cuales han sido elaboradas y concertadas con instancias como el Consejo Municipal de Planeación y el Concejo Municipal.

\section{Mapa 5: Áreas generadoras de plusvalía.}
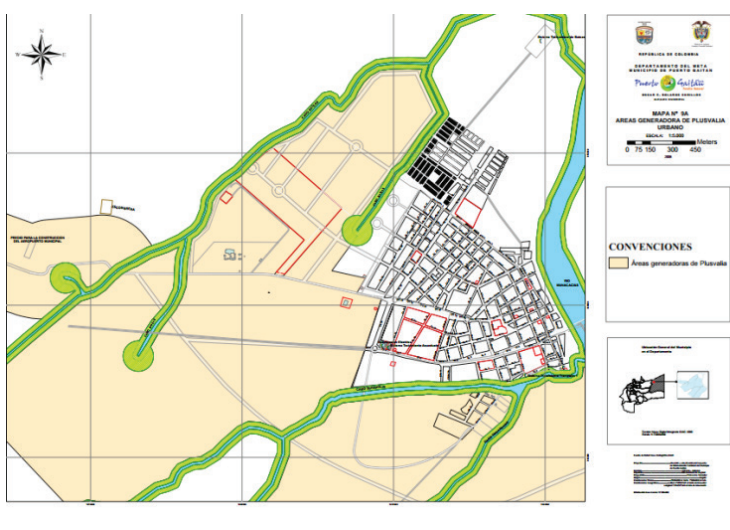

Fuente: EOT, Puerto Gaitán, 2009

La "plusvalía" es un concepto diferente de "valorización" y se genera por el mayor valor o "ganancia" que un particular obtiene de un predio por una vez, la cual se comparte con la administración municipal en una tasa determinada también por la Ley.

La complejidad del territorio rural municipal de Puerto Gaitán se deja ver con los diferentes mapas temáticos que se elaboran en desarrollo de la legislación nacional y local. Entre los enunciados podemos ver el siguiente de "soporte ambiental" del municipio:
Mapa 6: Soporte Ambiental.



Fuente: EOT Puerto Gaitán.

De acuerdo con la nomenclatura, el municipio definió un área de reserva forestal en la margen derecha del río Yucao, a lo largo de la jurisdicción municipal, hasta su desembocadura en el río Meta. Así mismo se determinan "áreas de reserva forestal protectora y productora" con una amplitud aproximada de 100 metros alrededor de los bosques y las "áreas de especial importancia ecosistémica" con una amplitud aproximada de $30 \mathrm{mts}$ alrededor de los cuerpos de agua. (EOT, 2009)

\subsection{POBLACIÓN INDÍGENA}

No obstante el número de indígenas que habita en el municipio, hasta la fecha no fue posible encontrar "planes de vida" de las comunidades residentes en estos resguardos. La participación de las comunidades indígenas en la formulación de los planes ha sido a través de los líderes $(\mathrm{Ca}-$ pitanes o Cabildos) y en particular por la Asociación de Resguardos Indígenas, Asociación Únuma.

Los líderes indígenas del municipio de Puerto Gaitán se dejan "atraer" a acuerdos mediante el uso de bebidas embriagantes (alicoramiento). En su mayoría, son los hombres quienes se desempeñan como capitanes. Las mujeres 
se mantienen vinculadas a las actividades domésticas de producción de alimentos en las "chagras" que se han constituido en los resguardos y en las comunidades dentro de dichos resguardos.

\section{ESTRUCTURAS ADMINISTRATIVAS MUNICIPALES}

La estructura administrativa es el eje al que articula toda la organización del territorio enmarcado en el plan de ordenamiento territorial. Pues así lo ordena la Constitución, cuando en su articulo segundo reza:

"Son fines esenciales del Estado: servir a la comunidad, promover la prosperidad general y garantizar la efectividad de los principios, derechos y deberes consagrados en la Constitución; facilitar la participación de todos en las decisiones que los afectan y en la vida económica, politica, administrativa y cultural de la Nación; defender la independencia nacional, mantener la integridad territorial y asegurar la convivencia pacífica y la vigencia de un orden justo” (Alcaldía de Bogotá, S/F).

Este propósito debe contar con una estructura acorde a las necesidades administrativas, que pueda dar cuenta de las demanda de la sociedad $\mathrm{y}$, de esta manera, cumplir con lo que promulga la Constitución en el artículo 311,

al Municipio como entidad fundamental de la división político administrativa del Estado le corresponde prestar los servicios públicos que determine la Ley, construir las obras públicas que demande el progreso local, ordenar el desarrollo de su territorio, promover la participación comunitaria, el mejoramiento social y cultural de sus habitantes y cumplir las demás funciones que le asignen la constitución y la ley (Alcaldía de Bogotá, S/F).

En el municipio de Puerto Gaitán, se encontraron tres (3) transformaciones administrativas. La primera transformación la realizó el Alcalde Mauro Cristobal Niño, en 1998. La segunda, en 2001, estuvo a cargo del Alcalde Oscar Bolaños Cubillos y una última en el 2008 que al igual que la anterior fue efectuada por Oscar Bolaños.

\subsection{NIVEL CENTRAL}

\subsubsection{Estructura Administrativa 1998-2000}

Puerto Gaitan, desde su creación como municipalidad, por mas de tres (3) decenios, fue un territorio considerado lejano, que pasó desapercibido, sin importancia para el nivel central y los demás territorios. Todo indicaba que Puerto Gaitan volvería a ser inspección del municipio de Puerto López, pues las deudas superaban los ingresos propios de la administración.

Un entrevistado, manifiesta que: "para esa fecha se acumulaban hasta tres salarios pues la administración no contaba con recursos para pagar la nómina" (Entrevistado22, 2013). Esta afirmación contrasta con lo que manifiesta otro entrevistado, donde comenta que: "los recursos propios basicamente dependian del impuesto predial y, que a los funcionarios se le adeudaban hasta tres (3) meses sin cancelarles el sueldo. De otra parte para pagarle a los funcionarios habia que salir a cobrarle a los finqueros y el que mas le aportaba en impuesto predial era el señor Víctor Carranza quien además era un colaborador permanente de la administración." (Entrevistado21, 2013)

Esto también lo corrobora, un concejal del presente período constitucional, quien comenta que: "en los años 99 y 2000 Puerto Gaitán era un municipio insostenible, por cuestiones de orden público, nadie pagaba impuestos. Los ingresos de la Nación eran de unos 800 millones, el primer año y el segundo unos 1.000 millones de pesos. Fue una situación muy dura, a los empleados se les demoraba el sueldo hasta tres, cuatro meses. A los concejales se les demoraba hasta un año para pagarles los honorarios. Por esa razón, casi pasamos a ser inspección de Puerto López. Gracias a una norma del Gobierno Nacional, que dijo que todos los municipios que debian dineros, el gobierno los pagaría, se pago la deuda. Deuda que había adquirido el alcalde Arnaldo Río Bueno, para comprar una maquinaría y construir la alcaldía (edificio) de Puerto Gaitán, y esa deuda se volvió insostenible." (Entrevistado2, 2012) 
Gráfica 1: Estructura Planta de Personal 1998-2000

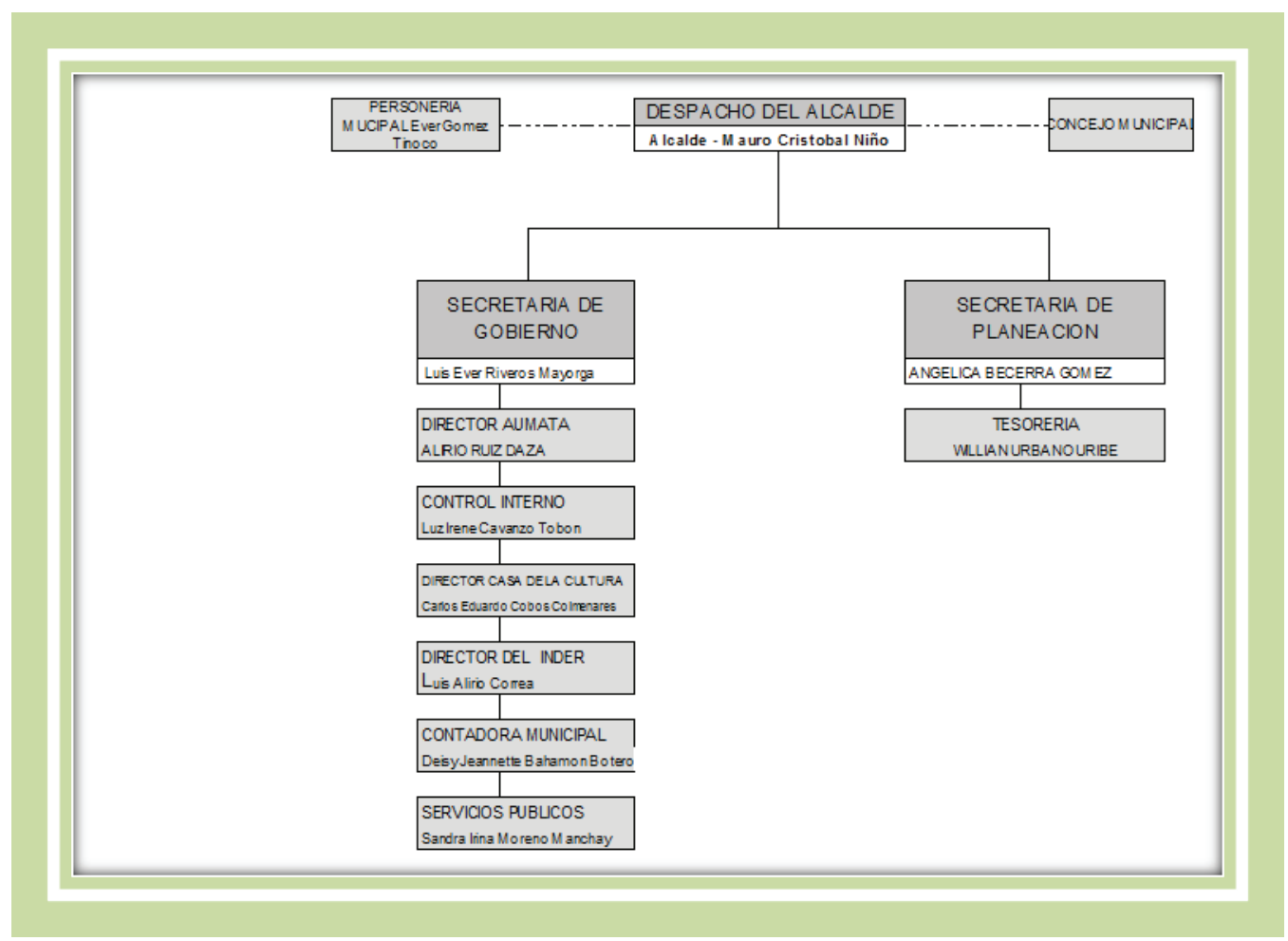

Fuente: Puerto Gaitan, 1998

En esta estructura la cabeza visible de la administración es el Alcalde Mauro Cristóbal Niño. Tambien cuenta con dos entes asesores que permiten realizar el control político y asesorar al Alcalde: La Personería y el Concejo municipal. De otra parte tiene una relación directa con dos Secretarías: la Secretaría de Gobierno y la de Planeacion. La Secretaría de Planeación tiene a su cargo las dependencias de la Umata, Control Interno, Casa de la Cultura, El Imder, el Contador Municipal y Servicios Públicos. La Secretaría de Planeación tiene a su cargo la Tesorería.

\subsubsection{Numero de Funcionarios}

Se realiza una aproximación a la administración en los años 90's de acuerdo con las entrevistas realizadas: "cuando ingresé a la administración en el año 1996 la Alcaldía contaba con veinte (20) funcionarios aproximadamente. Había diez personas en carrera administrativa. En mi caso entre por derecho propio sin ningún tipo de concurso al igual que los nueve compañeros" (Entrevistado22, 2013)
Un ex funcionario, quien en su momento se desempeñaba como gerente de la Empresa de Servicios Públicos de la municipalidad manifiesta que: "cuando yo llegue acá (2001) no había jurídico, los jurídicos éramos los Secretarios, nosotros revisábamos y asumíamos toda la responsabilidad. La administración contaba con veintiséis funcionarios de los cuales habian 12 en carrera administrativa, estos eran los de servicios generales, los conductores y los celadores todos ellos vinculados a la carrera por derecho propio. También había funcionarios de libre nombramiento y remoción, el secretario de gobierno, el de planeación, el de control interno." (Entrevistado21, 2013).

Con el objeto de conocer sobre el nombramiento por carrera administrativa se pregunto a un entrevistado ¿Cómo se selecciona a los funcionarios por carrera? Su respuesta fue: "a los de carrera administrativa se les hacian las pruebas, se hacia todo el proceso. Yo estuve en un proceso porque se necesitaba vincular un personal e hicieron todo el proceso con el acompa- 
ñamiento de la ESAP.” (Entrevistado21, 2013) Igualmente al entrevistar a una funcionaria, quien se ha desempeñado en diferentes cargos en la administración municipal, se preguntó: ¿Qué cargos ha desempeñado durante la administración? "Yo empecé como auxiliar de servicios generales, asi duré un año, luego como escribiente, manejé presupuesto estando en el mismo cargo y más o menos en el 94 fui Secretaria de gobierno. Debido a que no se necesitaba gran experiencia, y posteriormente de una reestructuración, quedé como Secretaria de la Alcaldía. Posteriormente quede en carrera administrativa, pero en otra reestructuración, el cargo cambio de nombre y yo sali de carrera." (Entrevistado1, 2012)

Se pueden observar tres (3) tipos de contratación al funcionariado: Por libre nombramiento y remoción, por provisionalidad y por carrera administrativa. Así las cosas, de los 26 fun- cionarios de la administración, tres (3) eran de libre nombramiento y remoción, doce (12) de carrera administrativa, mientras que 11 estaban en provisionalidad.

Para el nombramiento de los funcionarios de libre nombramiento y remoción un entrevistado ha dicho: "los cargos directivos son politicos, a veces se hace por méritos, porque son personas que tienen muchos conocimientos, que conocen la región, o que ha trabajado mucho con la comunidad, eso se tiene mucho en cuenta, que sean de Puerto Gaitán”. (Entrevistado 21, 2013)

\subsubsection{Estructura administrativa $2001-2007$}

El Alcalde Oscar Bolaños, expide el decreto 082 de julio 18 de 2001. A continuación se ilustra de manera gráfica la estructura administrativa de la planta global del municipio.

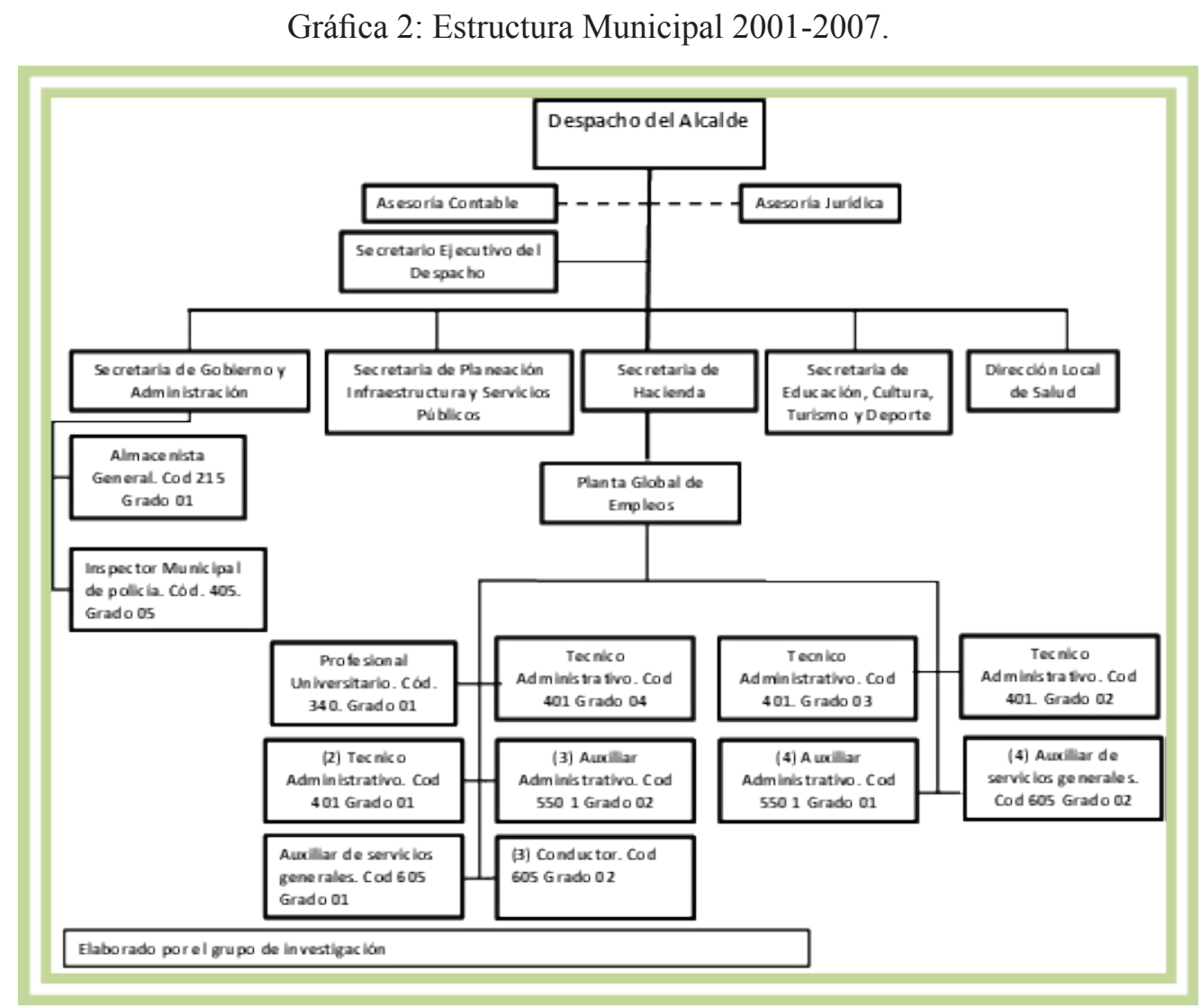

Fuente: Puerto Gaitan, Decreto 082 de julio 18 de 2001 
La gráfica permite visualizar que esta estructura es más compleja, con respecto a la del período que termina en 2001. Aparecen dos cargos de asesoría: contable y jurídica. Igualmente aparece el cargo de Secretario Ejecutivo del despacho. De otra parte se observa que son cuatro (4) Secretarías. Se han creado dos (2) Secretarías. La Secretaría de Hacienda y la Secretaría de Educación y Cultura, lo mismo que la Dirección de Salud. También hay un sistema de nomenclatura para los cargos que fue aprobado por el Concejo según Acuerdo 031 del 29 de noviembre de 2001. En síntesis esta nueva estructura muestra que la administración se comienza a profesionalizar y un nivel mas de exigencia para acceder a los mismos.

\subsubsection{Numero de funcionarios}

La nueva estructura y la planta de cargos asciende a 33 funcionarios sin incluir, el Alcalde y los dos asesores de la administración, es decir, que hay un aumento de 8 funcionarios.

En carrera administrativa la anterior estructura contaba con 12 personas. En cuanto a los cargos provisionales, se mantienen en doce (12), uno en el nivel profesional, cinco en el nivel técnico y seis del nivel asistencial (Decreto 108 de 2005, Alcaldía Municipal de Puerto Gaitan). Lo anterior, sin tener en cuenta los cargos que pasaron de carrera administrativa a la provisionalidad.

Tabla 2: Ajuste a la Planta de Cargos.

\begin{tabular}{|c|c|c|c|c|}
\hline NIVEL & $\begin{array}{c}\text { NOMBRAMIENTO } \\
\text { PROVISIONAL }\end{array}$ & ENCARGO & SIN PROVEER & TOTAL \\
\hline ASESOR & & & & \\
\hline PROFESIONAL & 1 & & 2 & 3 \\
\hline TECNICO & 5 & & & 5 \\
\hline ASISTENCIAL & 6 & & 2 & 8 \\
\hline TOTAL & 12 & 4 & 16 \\
\hline
\end{tabular}

Fuente: Puerto Gaitán (2005a)

La tabla permite observar que la estructura tenía 12 funcionarios en provisionalidad. Tal como ya se había señalado en los anteriores párrafos. Por otra parte se tiene que son cuatro (4) funcionarios en los que tiene que ajustarse la estructura es decir, dos (2) profesionales más y dos (2) asistenciales. Así las cosas la estructura completa, en provisionalidad, sería de diez y seis funcionarios: Tres (3) profesionales, cinco (5) técnicos y ocho (8) asistenciales.

\subsubsection{Estructura Administrativa del 2008 al 2011}

La nueva planta cuenta con 50 funcionarios, un aumento de más del 50\%. Según algunas explicaciones, se debió a las nuevas condiciones poblacionales y financieras, las cuales hacen que el municipio sea atractivo para muchas personas, sobre todo a aquellos que van en busca de trabajo.
De acuerdo a lo anterior un entrevistado ha dicho lo siguiente: La población en el año 1996 era de unos 4.500 habitantes, ahora estamos alrededor de los 18.000 o 20.000 habitantes, sólo en la cabecera municipal, sin incluir a Rubiales $u$ otras industrias. Entonces ese crecimiento de demandas hace necesario el crecimiento de la estructura municipal." (Entrevistado21, 2013)

En esta estructura aprobada durante la administración del Alcalde Oscar Bolaños, se observa que unas Secretarías desaparecen y se crean otras.

Los cargos de Asesoría contable y jurídica desaparecen. Estas funciones son asumidas por las nuevas Secretaria: Administrativa y Financie$\mathrm{ra}$, que a su vez retomará las funciones de la antigua Secretaría de Hacienda, mientras que la Secretaría de Gestión Jurídica se encargara de los temas de contratación, como también la 
Gráfica 3: Estructura Planta de Personal 2008-2011

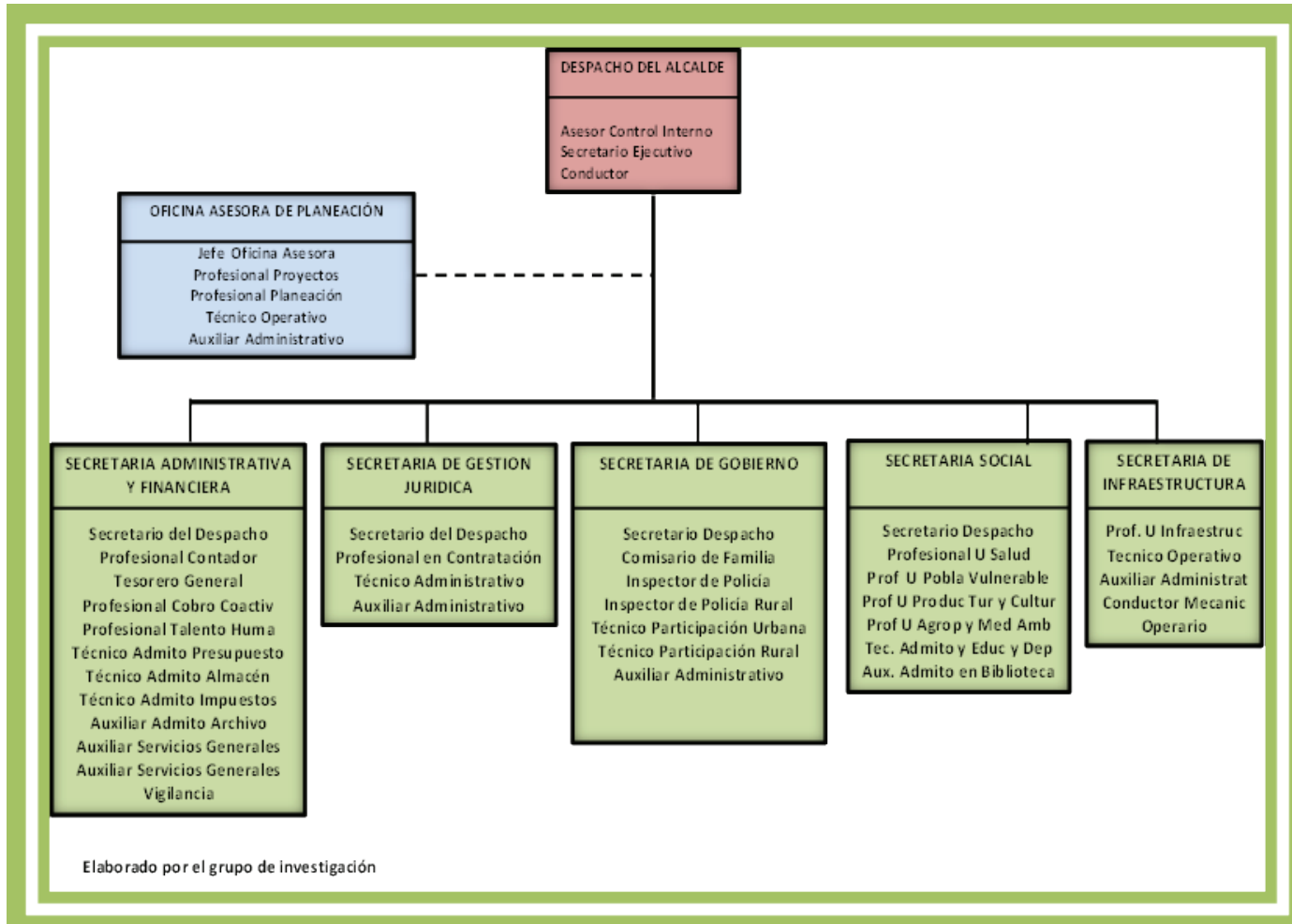

Fuente: Puerto Gaitán (2008 a)

asistencia jurídica al despacho del Alcalde y a las demás dependencias.

La Secretaría de Planeación es transformada en una Oficina Asesora. Se crea la Secretaría de Infraestructura, quien se encargara de la construcción, mantenimiento, y conservación de las obras públicas que demande la municipalidad.

Desaparecen la Dirección de Salud y la Secretaría de Educación y Cultura, y pasan bajo la responsabilidad de la Secretaría Social, que además, debe atender todo lo relacionado con población desplazada y discapacidad funcional, entre otros.

La profesionalización del funcionariado es una consecuencia de la complejidad de las estructuras y, que además es una exigencia de la Ley 909 de 2004 al referirse en el artículo dos " $L a$ profesionalización de los recursos humanos al servicio de la Administración Pública que busca la consolidación del principio de mérito y la calidad en la prestación del servicio público a los ciudadanos". (Ley 909)

Algunas reflexiones las han realizado expertos que han dicho que la profesionalización y especialización es la ruta para que la administración pública provea de servicios eficientes y efectivos con resultados e impactos importantes en la sociedad. (Longo y Iacoviello, 2013)

Al respecto Zuluaga manifiesta "La globalización demanda instituciones públicas más fuertes y flexibles y es el concepto de la gerencia de lo público lo que permite la formación de una nueva élite de servidores públicos". (Zuluaga, 2004,117)

De otra parte Jiménez afirma que "la emergencia de los Estados nacionales centralizados en Europa reclama la necesidad de nuevos conocimientos y funcionarios calificados para la viabilidad del nuevo tipo de ordenamiento (ejércitos permanentes, relaciones entre Esta- 
dos, recaudación de impuestos, administración de justicia, obras públicas, comercio marítimo, etc.)". (Jiménez, 2005)

Otros expertos sostienen que hay una deuda con la carrera administrativa y la profesionalización del funcionariado por la falta de compromiso político "el bajo compromiso político, esencialmente de los miembros del Congreso de la República, para hacer efectivo el proceso de profesionalización de la función pública, es decir, que para el congresista resulta de mayor interés personal y electoral fortalecer su red clientelista, antes que propender por la tecnificación de los cuerpos burocráticos que integran las diferentes agencias gubernamentales". (Martínez, 2010, 118)

\subsection{Nivel descentralizado}

Empresa de servicios públicos Perla del Manacacías. Es una entidad del orden municipal descentralizado, con naturaleza industrial u comercial, con autonomía jurídica, administrativa y financiera, con una estructura orgánica, quien tiene una junta directiva, integrada por un Gerente, un Tesorero, una Secretaria, un Almacenista, un Técnico de facturación, un Contador externo. La entidad presta los servicios de acueducto, alcantarillado y aseo (Empresa de servicios públicos Puerto Gaitán, 2013)

El servicio de acueducto. Según datos de la empresa se tienen 1.331 usuarios, con cobertura del 95\%. El servicio se presta por turnos de 4 horas diarias. Su potabilidad es parcialmente, lo que requiere de altos tratamientos. Así se ha referido algunos entrevistados sobre el servicio de agua del municipio. "En cuanto al agua 90\% de los habitantes poseen pozo profundo de hasta 25 metros de profundidad." (Entrevistado26, 2013), igualmente así lo expresa un empresario: "aún no se tiene agua para toda la población porque todavía tenemos deficiencias, además el agua la colocan por horas, es decir que el servicio no es constante."(Entrevistado4, 2012). También lo expresa un poblador: "no hay acueducto. Aqui la gente saca el agua de pozos con motobomba, los que no tienen pozos deben esperar a que les ponga el agua una o dos horitas. Uno ve en contraste mega obras y no un buen servicio de acueducto." (Entrevistado10, 2012)

Servicio de alcantarillado. Son 1145 usuario con los que cuenta este servicio, con una cobertura del $80 \%$ en el área urbana, con una planta de aguas servidas (Empresa de servicios públicos Puerto Gaitán, 2013).

Por otra parte el servicio de aseo se transporta al municipio de Villavicencio, con 1.650 usuarios, con servicio dos veces semana (Empresa de servicios públicos Puerto Gaitán, 2013). Un concejal manifiesta: "tenemos un gran problema con las basuras, porque los carros que tenemos, no le pueden atender la cantidad de desechos que produce el municipio. Pero el OCAD ya nos aprobó un proyecto para un relleno sanitario aquí en Puerto Gaitán y con eso dar cumplimiento a la recolección de basuras." (Entrevistado2, 2012). También un empresario comenta que: "Es un mal servicio, creo que pasan una vez cada veinte dias, no hay un horario definido, por lo que la gente saca la basura, porque en algún momento tiene que pasar y después de un día coge mal olor la basura. Me dijeron que al municipio le sale muy costoso el tema de las basuras, porque tiene llevarla hasta Villavicencio. Al parecer cada viaje cuesta una millonada, entonces, yo no entiendo por qué si hay tanto espacio no hacen el relleno. Eso es una inoperancia absoluta." (Entrevistado10, 2012)

\section{NÓMINAS ADMINISTRATIVAS (PERSONAL DE CARRERA, CPS)}

Para lograr la aproximación en la evolución de empleo público en el municipio de Puerto Gaitán, se presentan dos tablas. Una muestra las diferentes modalidades de contratación en el período de estudio y la otra en la que se muestra la contratación de prestación de servicios del 2000 al 2011 en cada una de las dependencias

\subsection{TENDENCIAS EN LAS NÓMINAS ADMINISTRATIVAS.}

Cada una de las transformaciones implica un patrón de cambio institucional. Sobre el asunto se han referido Oreen, Skowronek y Thelen, quienes, citados por Saavedra, sostienen que los 
patrones de cambio institucional, "se describen como procesos mediante los cuales, a través de sucesivas reformas, se adicionan nuevas reglas a las ya existentes que se resisten a cambiar. El resultado es un patrón institucional deshilvanado e incoherente; un añadido de reglas con diferentes lógicas las cuales compiten entre sí tratando de regular el comportamiento de los miembros de las organizaciones". (Saavedra Echeverry, 2012)

Se identifica la tendencia de contratación que algunos expertos denominan "botín político". Así lo define Jiménez Benítez quien dice que es "aquella concepción de que todos los cargos públicos deben ser desempeñados por personas adeptas al movimiento político que obtenga la victoria electoral o simplemente que detente el poder". (Jiménez Benítez, 2005, p. 5). Otros expertos la han denominado el "clientelismo político" (Martínez Cárdenas \& Ramírez Mora, 2012, p. 84)

Por otra parte Gómez citado por Martínez y Ramírez manifiesta que: “...la burocracia clientelista, entendida está por la sistemática sustitución de empleados públicos elegidos meritocráticamente por otros elegidos clientelarmente, como un elemento que degenera los principios de la burocracias estructuradas, permite una tolerancia que puede justificar la perpetuación de los empleados públicos (probablemente corruptos) en sus cargos y contribuye a la creación de una burocracia desorganizada, que por obvia razones, propicia la corrupción situación que se tiende a generalizar debido a la baja sanción moral" (Martínez Cárdenas \& Ramírez Mora, 2012, p. $86,87)$.

Frente a esta tendencia el Ministerio del Trabajo junto con el Departamento Administrativo de la Función Pública expidieron dos circulares, una en noviembre de 2011 y la otra el 08 de febrero de 2012. (Vivas C, Younes M, Peña B, \& Torres V , 2012).

Una mirada a lo sucedido en el período de 2000 -2011 de la municipalidad de Puerto Gaitán:

Tabla 6: tipo de vinculación 2000- 2011

\begin{tabular}{|c|c|c|c|c|c|c|c|c|c|c|}
\hline \multirow[t]{2}{*}{ AÑOS } & \multicolumn{2}{|c|}{$\begin{array}{l}\text { CARRERA } \\
\text { ADMINISTRATIVA }\end{array}$} & \multicolumn{2}{|c|}{ PROVISIONALIDAD } & \multicolumn{2}{|c|}{$\begin{array}{l}\text { LIBRE } \\
\text { NOMBRAMIENTO } \\
\text { Y REMOCIÓN }\end{array}$} & \multicolumn{2}{|c|}{$\begin{array}{l}\text { CONTRATO } \\
\text { PRESTACIÓN DE } \\
\text { SERVICIOS }\end{array}$} & \multicolumn{2}{|l|}{ TOTALES } \\
\hline & CONTRATOS & $\%$ & CONTRATOS & $\%$ & CONTRATOS & $\%$ & CONTRATOS & $\%$ & CONTRATOS & $\%$ \\
\hline 2000 & 12 & 38 & 11 & 34 & 3 & 9 & 6 & 19 & 32 & 2,89 \\
\hline 2001 & 12 & 33 & 12 & 33 & 6 & 17 & 6 & 17 & 36 & 3,25 \\
\hline 2002 & 12 & 33 & 12 & 33 & 6 & 17 & 6 & 17 & 36 & 3,25 \\
\hline 2003 & 12 & 33 & 12 & 33 & 6 & 17 & 6 & 17 & 36 & 3,25 \\
\hline 2004 & 12 & 33 & 12 & 33 & 6 & 17 & 6 & 17 & 36 & 3,25 \\
\hline 2005 & 12 & 30 & 16 & 40 & 6 & 15 & 6 & 15 & 40 & 3,61 \\
\hline 2006 & 12 & 30 & 16 & 40 & 6 & 15 & 6 & 15 & 40 & 3,61 \\
\hline 2007 & 12 & 30 & 16 & 40 & 6 & 15 & 6 & 15 & 40 & 3,61 \\
\hline 2008 & 4 & 3 & 22 & 14 & 8 & 5 & 123 & 78 & 157 & 14,18 \\
\hline 2009 & 4 & 2 & 38 & 15 & 8 & 3 & 197 & 80 & 247 & 22,31 \\
\hline 2010 & 4 & 2 & 38 & 20 & 8 & 4 & 143 & 74 & 193 & 17,43 \\
\hline 2011 & 4 & 2 & 38 & 18 & 8 & 4 & 164 & 77 & 214 & 19,33 \\
\hline TOTALES & 112 & 10 & 243 & 22 & 77 & 7 & 675 & 61 & 1107 & 100 \\
\hline
\end{tabular}

Elaboración: Elaboración Grupo de investigación 
En los puestos de carrera administrativa se mantuvieron en 12 personas, que equivalen al $28 \%$ de la nómina total del año 2000. En este período sucedieron dos (2) modernizaciones o reestructuraciones. Para el período 2008 al 2011 sucede una nueva modernización en cabeza del entonces Alcalde, Oscar Bolaños, reduciendo el número de vinculaciones a cuatro (4) personas. Por versiones de algunos entrevistados, esto se debió al cambio de denominación del cargo y en otros casos, porque los cargos fueron suprimidos. La pérdida de nombramientos por este tipo de contrato es de 8 personas, lo que equivale en términos porcentuales al $28 \%$.

Los contratos por provisionalidad, entre los períodos del 2000 al 2007, tuvieron un comportamiento de leve incremento al pasar de 11 cargos en el 2000, a 16 cargos en el 2007, un ascenso tan sólo del 7\% en 8 años. Ahora, si observamos el período comprendido entre el 2008 y el 2011 esta modalidad, de contar con 16 cargos en el primer año, paso a tener 38 en el 2011. Se puede decir que aumentó en el 58\% en tan sólo 4 años. Los contratos de libre nombramiento y remoción se incrementan en la medida en que la municipalidad se moderniza, así las cosas, para el 2000 la estructura municipal contaba con 3 cargos que correspondía a dos Secretarías y una Dirección. Para el 2011 este número se aumenta a 8, un incremento de 5 cargos en 10 años.

Los contratos de prestación de servicios, CPS, presentan el siguiente comportamiento: entre los años 2000- 2007, hubo sólo en seis (6), cada año. Pero para el período 2008- 2011 el número se incrementó a 164 contratos lo que representa un aumento de más del $2000 \%$

A continuación se presenta una gráfica que muestra las tendencias por modalidad durante el período estudiado.

La contratación por prestación de servicios, CPS, se incrementa a partir del año 2008, con un tope máximo de contratación en el 2009 de 247 contratos, disminuyendo en el 2010 y volviendo a incrementarse en el 2011. La tendencia de la municipalidad desde los inicios de la tercera reestructuración es al incremento de la nómina de funcionarios y de su "burocracia",
Gráfica 4: Comportamiento por modalidad de contratación 2000- 2011

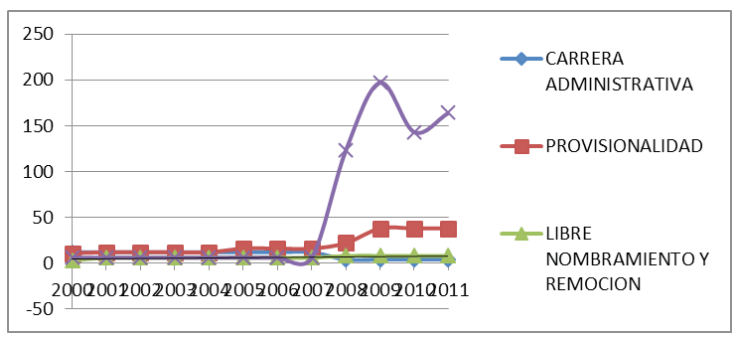

Fuente: Elaboración Grupo de investigación

mediante la contratación de prestación de servicios.

Así lo sostiene el uno de los concejales entrevistados: "Por cuestión del petróleo hay una gran cantidad de personas que se vienen para Puerto Gaitán, ejemplo, si antes teníamos 2.000 estudiantes ahora tenemos 6.000. Entonces no habrá recurso que alcance para cubrir esta demanda. Desde que haya población flotante no habrá recurso que aguante. Al día de hoy tenemos unos 24.500 afiliados al régimen subsidiado, 11.000 en el régimen contributivo, más la población flotante, o sea, tenemos alrededor de unos 40.000 habitantes". (Entrevistado2, 2012)

Otro entrevistado, inicialmente se aprobaron 72.000 millones de pesos, pero como han llegado ingresos de regalías ahora estamos en unos 100.000 millones de pesos." (Entrevistado2, 2012)

Los contratos por prestación de servicios del 2000 al 2007, se mantuvieron en seis (6) por esta modalidad. La Secretarías con el mayor número de contratos de prestación de servicios, durante este período, fueron Educación que realizó dieciséis (16) y Planeación doce (12) contratos. Es de recordar que esta entidad territorial para estos períodos los recursos propios eran bajos y existía una gran dependencia por las transferencias del sistema general de participaciones.

En el 2008 se contrataron 123 personas, distribuidas de la siguiente manera: 38 en gobierno que representa el 31 por ciento, 15 para gestión jurídica que representa el 12 por ciento, 8 para administrativa y financiera que corresponde al 7 
Tabla 8: contratos de prestación de servicios en el período 2000- 2011

\begin{tabular}{|c|c|c|c|c|c|c|c|c|c|c|c|c|c|c|c|c|c|c|c|}
\hline \multirow[t]{2}{*}{ AÑOS } & \multicolumn{2}{|c|}{ GOBIERNO } & \multicolumn{2}{|c|}{ PLANEACION } & \multicolumn{2}{|c|}{ HACIENDA } & \multicolumn{2}{|c|}{$\begin{array}{l}\text { EDUCACION } \\
\text { Y TURISMO }\end{array}$} & \multicolumn{2}{|c|}{$\begin{array}{l}\text { DIRECCION } \\
\text { SALUD }\end{array}$} & \multicolumn{2}{|c|}{$\begin{array}{l}\text { GESTION } \\
\text { JURIDICA }\end{array}$} & \multicolumn{2}{|c|}{$\begin{array}{c}\text { ADMINISTRA } \\
\text { TIVA Y }\end{array}$} & \multicolumn{2}{|c|}{ SOCIAL } & \multicolumn{2}{|c|}{ NFRAESTRUCTURA } & \multirow{2}{*}{$\begin{array}{c}\text { TOTAL } \\
\text { CONTRATOS }\end{array}$} \\
\hline & No Cont $\mid \%$ & & \begin{tabular}{|l|l} 
No Cont & 9
\end{tabular} & $\%$ & No Cont & & No Cont $\%$ & & No Cont $\%$ & & No Cont & $\%$ & No Cont $\mid \%$ & & No Cor $\%$ & & No Cont & $\%$ & \\
\hline 2000 & 2 & 33 & 1 & 17 & & & 2 & 33 & 1 & 17 & & & & & & & & & 6 \\
\hline 2001 & 1 & 17 & 2 & 33 & 2 & 33 & 1 & 17 & & & & & & & & & & & 6 \\
\hline 2002 & 1 & 17 & 2 & 33 & & & 2 & 33 & 1 & 17 & & & & & & & & & 6 \\
\hline 2003 & 3 & 50 & 2 & 33 & & & 1 & 17 & & & & & & & & & & & 6 \\
\hline 2004 & & & 2 & 33 & & & 1 & 17 & 3 & 50 & & & & & & & & & 6 \\
\hline 2005 & 2 & 33 & 1 & 17 & & & 2 & 33 & 1 & 17 & & & & & & & & & 6 \\
\hline 2006 & 1 & 17 & & & & & 5 & 83 & & & & & & & & & & & 6 \\
\hline 2007 & 2 & 33 & 2 & 33 & & & 2 & 33 & & & & & & & & & & & 6 \\
\hline 2008 & 38 & 31 & & & & & & & & & 15 & 12 & 8 & 7 & 34 & 28 & 28 & 23 & 123 \\
\hline 2009 & \begin{tabular}{l|l}
42 \\
\end{tabular} & 21 & & & & & & & & & 14 & 7,1 & 12 & 6 & 82 & \begin{tabular}{l|l}
42 & -120
\end{tabular} & 47 & 24 & 197 \\
\hline 2010 & 31 & 22 & & & & & & & & & 15 & 10 & 13 & 9 & 49 & 34 & 35 & 24 & 143 \\
\hline 2011 & 27 & 16 & & & & & & & & & 7 & 4 & 10 & 6 & 65 & 40 & 55 & 34 & 164 \\
\hline TOTALES & 150 & 22 & 12 & 2 & 2 & 0 & 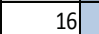 & 2 & \begin{tabular}{l|l}
6 & $-2 \cdot a$ \\
\end{tabular} & 1 & 51 & 8 & 43 & 6 & 230 & 34 & 165 & 24 & 675 \\
\hline
\end{tabular}

Fuente: Elaboración Grupo de investigación

por ciento, 34 para secretaria social que corresponde al 28 por ciento y 28 para infraestructura que corresponde al 23 por ciento. Esto quiere decir que la Secretaria que más contrato por esta modalidad fue Gobierno.

Para el período 2009, los contratos fueron 197. La Secretaría que más apoyo tuvo por este tipo de contratación fue la Social, con participación del 42 por ciento, seguida de la Secretaría de Infraestructura con el 24 por ciento.

En el 2010, los apoyos para las Secretarías fueron de 143 personas. En este año nuevamente la Secretaria Social es la que más contratación de personal tiene con 49 que co- rresponde al 34\%, seguida de la Secretaria de infraestructura.

En este último período de estudio 2011, los contratos por prestación de servicios fueron de 164. Bajo esta modalidad la Secretaría Social, fue la que más contratos realizó con 65 , que corresponde al 40 por ciento, seguida nuevamente de la Secretaría Infraestructura.

\subsection{INVESTIGACIONES DISCIPLINA- RIAS, FISCALES Y JUDICIALES}

Otro fenómeno que se ha visto incrementado en los últimos años es el de las investigaciones sobre los administradores locales.

Tabla 7: Vinculados a proceso de investigación en la Contraloría Departamental

\begin{tabular}{|l|l|l|}
\hline $\boldsymbol{A} \tilde{\boldsymbol{N} O}$ & NOMBRE DEL VINCULADO & CARGO \\
\hline 2010 & Oscar Edwin Bolaños Cubillos & Alcalde \\
\hline 2010 & Jaime Apolonio Ballesteros Cantillo & Ex-Alcalde \\
\hline 2009 & Andrés Ricardo Pinillos & Ex-Gerente Empresa de Servicios Públicos. \\
\hline 2009 & Henry Alberto Villamarín & Ex-Gerente Empresa de Servicios Públicos. \\
\hline 2009 & Saidy Yurely Caicedo Vargas & Almacenista \\
\hline 2009 & Edwin Enciso Martínez & Gerente Empresa Servicios Públicos. \\
\hline 2009 & Adriana Amaya Ayala & Gerente Empresa Servicios Públicos. \\
\hline 2009 & Oscar Edwin Bolaños Cubillos & Alcalde \\
\hline 2009 & Jaime Apolonio Ballesteros Cantillo & Alcalde \\
\hline 2009 & Luis Felipe Piñeros & Supervisor \\
\hline 2008 & Oscar Edwin Bolaños Cubillos & Alcalde \\
\hline 2008 & Jaime Apolonio Ballesteros Cantillo & Director \\
\hline 2008 & Alberto Rojas Segura & Agente Liquidador \\
\hline 2005 & Jaime Apolonio Ballesteros Cantillo & Alcalde \\
\hline
\end{tabular}




\begin{tabular}{|l|l|l|}
\hline 2005 & Edwin Enciso Martínez & Almacenista \\
\hline 2003 & Oscar Edwin Bolaños Cubillos & Alcalde \\
\hline 2003 & Flor Diana Sabogal Villalobos & Interventora \\
\hline 2003 & Fernando Abella Yepes & Gerente \\
\hline 2003 & Fernando Villalobos Rodríguez & Presidente del Consejo \\
\hline 2001 & Oscar Edwin Bolaños Cubillos & Alcalde \\
\hline 2001 & Flor Diana Sabogal Villalobos & Interventora \\
\hline 2000 & Mauro Cristóbal Niño & Alcalde \\
\hline 2000 & Iván Vergaño Vásquez & Auxiliar Farmacia \\
\hline 2000 & William Urbano Uribe & Tesorero \\
\hline 1999 & Arnaldo Riobueno Riveros & Alcalde \\
\hline 1999 & Mauro Cristóbal Niño & Alcalde \\
\hline 1999 & Jorge E. Acosta & Almacenista \\
\hline 1999 & Álvaro Díaz Vargas & Inspector Obras Publicas \\
\hline 1998 & Wilson Javier Barreto Alfonso & Medico Director Hospital \\
\hline 1998 & Gilberto Acosta & Administrador \\
\hline 1998 & Omar Prada López & Rector \\
\hline 1998 & Carlos Arturo Carreño & Director Hospital \\
\hline 1998 & José Ricardo Quiñones & Medico \\
\hline 1998 & Jaime Ballesteros & Director \\
\hline 1998 & Tomas Gómez & Asistente Administrativo \\
\hline 1998 & Arnaldo Riobueno Riveros & Alcalde \\
\hline & & \\
\hline
\end{tabular}

Fuente: Contraloría Departamento del Meta, 2012

De acuerdo con los datos suministrados por la Contraloría Departamental de Meta son 36 funcionarios investigados.

El funcionariado que tiene procesos en estos períodos es en su mayoría directivo y Alcaldes, pues como ya se ha mencionado la administración va implementando nuevos procesos y procedimientos en la medida en que se incrementa el presupuesto y población, que son responsabilidad del cuadro directivo.

7. PRESUPUESTO MUNICIPAL (RECURSOS PROPIOS, SGP, FUNCIONAMIENTO, INVERSIÓN)

Abordaremos la dinámica de ingresos y gastos que presentó el municipio de Puerto Gaitán en el período 1998-2001.

\subsection{ANÁLISIS PRESUPUESTAL PUER- TO GAITÁN 1998-2011}

El municipio de Puerto Gaitán inició el período estudiado con un presupuesto de \$2.081.478.170 pesos. Para siguiente año tiene una variación positiva de 2\%. En el año 2000 el presupuesto creció en un 15\%. En el año 2001 hubo un in- cremento considerable al casi doblarse el presupuesto, con una variación de $80 \%$. En el 2002 y 2004 el presupuesto creció $17 \%$ y $48 \%$ respectivamente, mientras las transferencias decrecieron en $10 \%$ en el 2002 y crecieron en $90 \%$ en el 2004. En el siguiente año el presupuesto se incrementa en un $127 \%$. Lo que denota una mayor gestión de los recursos propios.

Hasta el año 2004 Puerto Gaitán tenía un grado de dependencia de las transferencias de $75 \%$ con excepción del año 2002, cuando bajó a 59\%, situación que se puede explicar por la diminución de las transferencias en un $10 \%$ con relación al año anterior. En los siguientes dos años el nivel de dependencia de las transferencias baja a un promedio de 46\%. En el 2007 el aumento de la dependencia se da por la disminución de los recursos de capital en un 88\%. En 2008 la dependencia se debe al aumento de las transferencias, pues aunque los recursos propios aumentaron (los tributarios aumentaron en un 94\%, las tasas multas y contribuciones en $2499 \%$ ) y los recursos de capital (aumentaron en 3204\%), las transferencias superaron los anteriores recursos en valores absolutos. En el año 2009 se denota una reducción del indicador por razón de la disminución de transferencias en un $9 \%$ ( $\$ 2.541$ millones de pesos). 
Gráfica 8: Ingresos Tributarios Puerto Gaitán 1998-2011

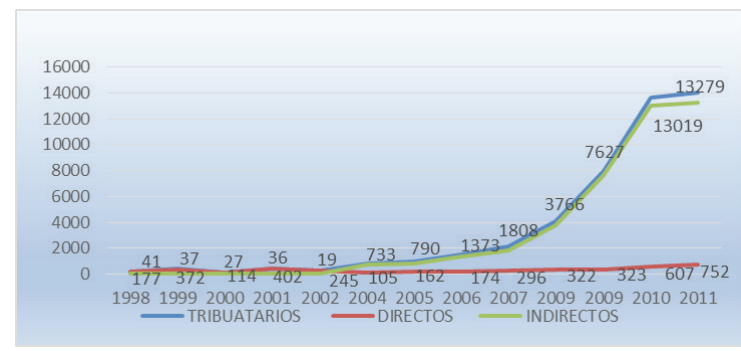

Fuente: Elaboración grupo de investigación

Entre 1998-2004 los impuestos fuertes eran los directos, del año 2005 en adelante los impuestos indirectos tomaron fuerza y terminaron siendo los recursos determinantes dentro del rubro Tributarios. Esto se puede explicar por la importancia de los impuestos Industria y Comercio dentro de los indirectos y el Impuesto Predial dentro de los directos.

El impuesto de Industria y Comercio tiene una gran influencia dentro de la sub serie. Este impuesto empieza teniendo una participación promedio del $41 \%$ sobre el total de los impuestos indirectos. En los siguientes tres años la participación fue del 29\%. Para el año 2002 la participación baja a un $5 \%$, de aquí en adelante el impuesto de Industria y Comercio empieza a jalonar los ingresos propios del municipio, logrando un promedio de crecimiento del $2331 \%$ durante los últimos 8 años.

\section{Gráfica 10: Impuestos Directos}

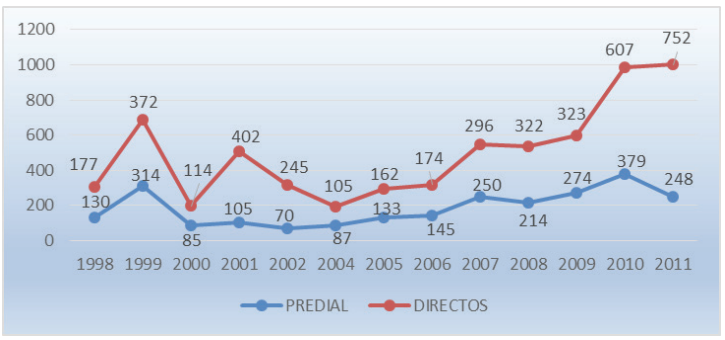

Fuente: Elaboración Grupo de Investigación

El cambio de posición dominante de los impuestos directos e indirectos dentro de los ingresos tributarios denota un cambio en la situación económica del municipio. El impuesto predial creció un promedio de $20 \%$ durante todo el pe- ríodo y los impuestos directos un 37\%. Los altos y bajos en la recolección de este impuesto se deben más al esfuerzo fiscal del municipio que a factores externos, como la economía.

\section{Gráfica 11: Importancia de los Recursos Propios}

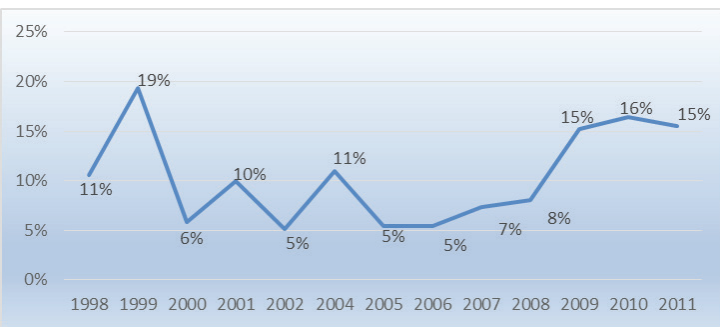

Fuente: Elaboración Grupo de Investigación.

El municipio presenta un promedio de un $10 \%$ durante todo el período de recursos propios. $\mathrm{Si}$ se observa de nuevo esta gráfica guarda relación con el impuesto de Industria y Comercio.

Gráfica 13: Autofinanciamiento del Funcionamiento



Mientras el municipio tenía en 1998 una capacidad para financiar su funcionamiento del $25 \%$, entre 1999 y 2001 sube al $49 \%$ y $65 \%$ respectivamente. En el 2002 baja el nivel y obtiene sólo un 22\%. A partir del año 2004 el municipio empieza a hacerse viable al lograr tener recursos para cubrir el $100 \%$ de sus gastos de funcionamiento.

\section{COMPORTAMIENTO ELECTORAL LOCAL}

Se presentará una descripción del comportamiento electoral en el período estudiado, tanto para la elección de Alcaldes, como de Concejales, de Gobernadores, Diputados y Representantes a la Cámara. 


\subsection{ELECCIÓN DE ALCALDES}

Durante el período 2000-2011 se realizaron en Puerto Gaitán cuatro elecciones de alcaldes y concejales $(2000,2004,2007,2011)$.

\subsubsection{Elecciones 2.000}

En la primera elección de Alcaldes de Puerto Gaitán en el período relacionado, se presentaron 3 candidatos, en su totalidad por el partido Liberal, por lo que obtuvo el $95 \%$ del total de la votación, el restante $5 \%$ se dividió entre votos en blanco $(1 \%)$, votos nulos $(2.5 \%)$, y Tarjetas no marcadas $(1.5 \%)$. La población de Puerto Gaitán eligió a Oscar E. Bolaños con un total de 1386 votos con un $54 \%$ del total de los votos (2583 votos), con una ventaja sobre el segundo en la lista de 594 votos.

\subsubsection{Elecciones 2.003}

En la segunda elección se presentaron 4 candidatos, el Partido Liberal perdió la hegemonía mostrada en las anteriores elecciones al presentar un sólo candidato. Los otros tres candidatos fueron por tres partidos diferentes. Sin embargo, el partido Liberal muestra su arraigo en la región con la elección de su candidato con una votación de 1552 votos, que corresponde al $52,9 \%$ del total de la votación. Con una diferencia con el segundo en la lista de 446 votos. El segundo candidato representando al partido Cambio Radical obtuvo un total de 1106 votos con un porcentaje de participación del 37,7\%. Los otros dos candidatos y sus respectivos partidos obtuvieron un $1,4 \%$ y $0,7 \%$ (ver tabla). El restante $7,2 \%$ de la votación se dividió entre el voto en blanco $(0,8 \%)$, votos nulos $(2 \%)$ y tarjetas no marcadas $(4,4 \%)$. En total votaron 2.933 personas de un potencial de 6.779 votantes, lo que da una abstención del 57\%.

\subsubsection{Elecciones 2.007}

Para estas elecciones se presentaron 5 candidatos, siendo elegido Oscar Eruin Bolaños con una votación de 2856,1266 votos más que la segunda en la lista. El partido Liberal sigue mostrando su fuerza en la región con la elección de su candidato obteniendo un $53,2 \%$ de la votación. El segundo partido en votación y su candidata obtuvieron un $29,6 \%$. Por su parte el voto el blanco obtuvo $0,7 \%$, los votos nulos un $1,6 \%$ y las tarjetas no marcadas un $2,8 \%$. El total de la votación fue de 5.372 que corresponde al $61 \%$ del potencial electoral, lo que da un porcentaje de abstención del 39\%.

\subsubsection{Elecciones 2011}

En estos comicios se presentaron 7 candidatos por diferente partido cada uno. Por primera vez el partido liberal pierde las elecciones en Puerto Gaitán en el período analizado, aunque el candidato ganador, por el partido de la U, había pertenecido a la administración del anterior Alcalde, Oscar Bolaños, como Personero. El Partido Social de Unidad Nacional impone su candidato con una votación de 3.277 votos, correspondientes al $32,2 \%$ con una diferencia del segundo de 605 votos, quien obtuvo un $26,2 \%$. El voto en blanco obtuvo un 1,4\%, los votos nulos un $3 \%$ y las tarjetas no marcadas un 3,2\%. La votación total fue de 10.187 votos sobre un potencial electoral de 15.665 , lo que da un porcentaje de abstención del 35\%.

La brecha entre la línea de votación total y la del candidato electo muestra una tendencia al distanciamiento, mientras la votación total registra el crecimiento expuesto en líneas anteriores, el crecimiento de la votación total con la que salieron elegidos los candidatos tuvo un crecimiento del $12 \%$ en el 2004 , del $84 \%$ en el 2007 y del 15\% en el 2011 .

\section{Gráfica 14: Comportamiento Votación, Puerto Gaitán, Meta, 2000-2011}

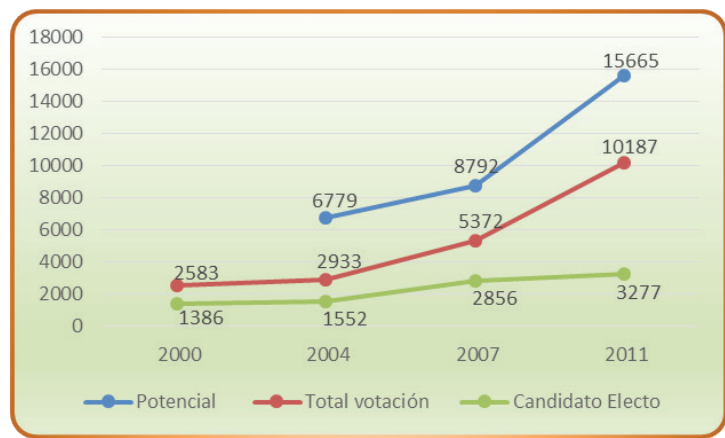

Fuente: Elaboración Grupo de Investigación 


\section{CONCEJO MUNICIPAL}

\subsection{GESTIÓN DEL CONCEJO (ACUER- DOS MUNICIPALES)}

En el período 1998-2000 fueron once los concejales electos, en su mayoría de profesión comerciantes, su filiación de partido político es Liberal y tan sólo una curul corresponde a Cambio Radical. Se toma este período, por cuanto el último año pertenece al estudio del presente documento.

Para el período 2003-2005 son trece (13) concejales electos, de los cuales cuatro de ellos repiten período, todos del Partido Liberal colombiano. Sólo una curul obtuvo el partido de Autoridades Indígenas. Al igual que el período anterior son 13 concejales, para un período constitucional de cuatro (4) años. Todos de profesión comerciantes, repiten período cuatro de ellos: José Nieve Marques, Fredy Riobueno Nieves, Pablo Alberto Ruiz Vargas y Fernando Villalobos Rodríguez.

Liberal seis (6) curules, Cambio Radical, obtiene cuatro (4) curules, Apertura liberal con una (1) curul, Alianza Social indígena una (1) curul y el Partido de la U con una (1) curul. En el nivel nacional hubo una explosión de nuevos partidos a partir de la reforma electoral en el 2003. Entre 2008-2011 son once (11) concejales electos. Al igual que el período anterior de diferentes partidos, pero con dominio aun del Partido Liberal con cinco (5) curules, quien pierde una con respecto al anterior período. El partido de la U tiene dos (2) curules, una más con respecto al período anterior, Alianza Social Indígena dos curules, una más que el período anterior.

El partido Cambio Radical no obtuvo candidatos electos. Convergencia Ciudadana y Colombia Democrática son partidos nuevos en este período obteniendo de una curul cada uno. En segundo lugar, se visibilizan varias profesiones entre los candidatos electos, se destaca la elección de un medico un ingeniero electricista, siendo la profesión de comerciante la predominante.

El año 2009, se constituye una sociedad economía mixta, cuyo objeto es el desarrollo de pro- cesos tecnológicos, la operación y prestación de servicios de internet. También se faculta al Alcalde para tramitar un empréstito por la suma de $(\$ 35.000 .000 .000)$, con el fin de financiar los proyectos del Malecón (30 mil millones), ciclo vía y alameda ambiental del Yucao al Alto Neblinas ( 5 mil millones). Por otra parte, se crea un fondo cuenta sin personería jurídica para vivienda de interés social, igualmente se establece la política pública de empleo en el municipio.

En el 2010 se aprueban dos autorizaciones al Alcalde para comprometer recursos de vigencias futuras. Una en mes de abril por (\$139.995.000.000.). La segunda en el mes de diciembre por (\$2.550.000.000), los cuales tendrán por objeto ejecutar proyectos prioritarios en diferentes sectores y programas del plan de desarrollo 2008-2011 "Capacidad para el Desarrollo".

\subsection{CONTROL POLÍTICO}

En el proceso de investigación no se encontraron evidencias del ejercicio de control político del Concejo sobre la Administración Municipal, entendido como citación a los Secretarios de Despacho a presentar informes o decisiones del Concejo de declarar "no grato" a un funcionario de la Administración, a lo largo del período estudiado.

\section{CONCLUSIONES}

Los procesos de planeación (2000-2011), evidencian el conocimiento técnico que ofrecen los expertos externos a la administración contratados por los diferentes Alcaldes. Los planes cumplen los aspectos formales de la Ley del Plan General de Desarrollo, sin embargo, en los diagnósticos (4 planes) no se hace mención de la compleja problemática de seguridad que diversos estudios realizados en el primer decenio del 2000.

Los planes de desarrollo municipal no incorporan la dinámica actividad petrolera que se empezó a establecer desde el 2001. En el período 2004-2007, por instrucciones de la Contraloría Departamental del Meta, la administración municipal tuvo que "ajustar" en dos oportunidades 
(2004 y 2005) el plan de desarrollo para "armonizarlo" con el Plan de Desarrollo Departamental y el Plan de Desarrollo Nacional.

La participación ciudadana es señalada como un deber ser. La presencia de las compañías petroleras ha incrementado la participación de los actores sociales en la formulación de la política social (planes de desarrollo) aunque no es clara la participación ciudadana en la ejecución ni en la evaluación de las de políticas públicas municipales.

Se ha redefinido la institucionalidad. Con la creación de nuevas Secretarías y la misma complejidad de la administración los cargos se profesionalizan y, con ello, las exigencias para la vinculación de un funcionario a la administración municipal.

Se pudo establecer que las modalidades de vinculación más estables, son superadas, en un alto margen, por la forma de vinculación de contrato de prestación de servicio temporal, CPS.

Por el aumento de población, Puerto Gaitán ha ido tomando fuerza en la participación de las votaciones departamentales. Se observa cómo en las primeras elecciones analizadas, tanto de Asamblea como de Gobernación, el municipio tuvo una participación del $1 \%$, aproximadamente, y en las últimas elecciones (2011) la participación es de alrededor del 3\%.

La gestión realizada por los concejales en este decenio, no fue significativa, teniendo en cuenta la información consignada en los proyectos de Acuerdo, a los cuales el grupo tuvo acceso.

La diversificación de partidos no es una situación local que ocurra únicamente a Puerto Gaitán, esto también es el resultado de la proliferación que se ha gestado a nivel nacional y que termina afectando la actividad electoral del municipio estudiado.

\section{REFERENCIAS BIBLIOGRÁFICAS}

Aguilar Villanueva, L. F. (2006). Gobernanza y Gestion Pública. Mexico.

Alcaldia de Bogota. (S/F). Constitución Politica de Colombia 1991. Recuperado el 30 de Septiembre de 2013, de http://www.alcaldiabogota.gov.co/sisjur/normas/Norma1.jsp?i=4125,

Camargo, N. (2004). Socialización de los niños y niñas en zonas de conflicto Armado. Bogotá: Universidad Nacional, Facultad de ciencias humanas, Departamento de Antropología .

Cepeda, I., \& Giraldo, J. (2012). Victor Carranza alias “el patrón”. Cota, Cundinamarca: Random House Mondadori S.A.S.

Contraloría Departamental. (2012). Funcionarios con procesos disciplinarios en Puerto Gaitan Meta. Villavicencio Meta.

Contraloría General de la República. (2006-a). Formato CDM 104, Municipio de Puerto Gaitán, Meta 2006. Villavicencio.

Contraloría General de la República. (2006-b). Formato CDM 105, Municipio de Puerto Gaitán, Meta, 2006. Villavicencio.

Contraloría General de la República. (2007-a). Formato CDM 104, Municipio de Puerto Gaitán, Meta, 2007. Villavicencio.

Contraloría General de la República. (2007-b). Formato CDM 105, Municipio de Puerto Gaitán, Meta, 2007. Villavicencio. 
Contraloría General de la República. (2008-a). Formato CDM 105, Municipio Puerto Gaitán, Meta, 2008. Villavicencio.

Contraloría General de la República. (2008-b). Formato CDM 105, Municipio Puerto Gaitán, Meta, 2008. Villavicencio.

Contraloría General de la República. (2009-a). Formato CDM 104, Municipio Puerto Gaitán, Meta, 2009. Villavicencio.

Contraloría General de la República. (2009-b). Formato CDM 105, Municipio Puerto Gaitán, Meta, 2009. Villavicencio.

Contraloría General de la República. (2010-a). Formato CDM 104, Municipio Puerto Gaitán, Meta, 2010. Villavicencio.

Contraloría General de la República. (2010-b). Formato CDM 105, Municipio Puerto Gaitán, Meta, 2010. Villavicencio.

Contraloría General de la República. (2011-a). Formato CDM 104, Municipio Puerto Gaitán, Meta, 2011. Villavicencio.

Contraloría General de la República. (2011-b). Formato CDM 105, Municipio Puerto Gaitán, Meta, 2011. Villavicencio.

Empresa de servicios públicos Puerto Gaitán. (2013). Puerto Gaitán. Recuperado el 20 de 10 de 2013, de http://puertogaitan-meta.gov.co/Entidades_descentralizadas.shtml?apc=1bxx-1-\&x=2358799

Entrevistado1. (30 de Octubre de 2012). Entrevistado1. (A. Abella, \& F. Rodriguez, Entrevistadores)

Entrevistado10. (5 de Diciembre de 2012). Entrevistado10. (W. Ladino, Entrevistador)

Entrevistado2. (30 de Octubre de 2012). Entrevistado2. (A. Abel, \& R. Fidel, Entrevistadores)

Entrevistado21. (22 de Octubre de 2013). Entrevistado21. (A. Abella, Entrevistador)

Entrevistado22. (23 de Octubre de 2013). Entrevistado22. (A. Abella, Entrevistador)

Entrevistado26. (22 de Octubre de 2013). Entrevistado26. (A. Abella, Entrevistador)

ESAP. (1 de Noviembre de 2002-a). Puerto Gaitán, Meta, 1999-2002, Matriz de Egresos. Obtenido de http://cdim.esap.edu.co/BancoConocimiento/P/puerto_gaitan_-_meta_-_pp_-_1995-2003/puerto_gaitan_-_meta_-_pp_-_1995-2003.asp

ESAP. (1 de Noviembre de 2003-a). Puerto Gaitán, Meta, 1995-2003, Matriz de ingresos. Obtenido de http://cdim.esap.edu.co/BancoConocimiento/P/puerto_gaitan_-_meta_-_pp_-_1995-2003/puerto_gaitan_-_meta_-_pp_-_1995-2003.asp

"ESPECIALES PIRRY" ORO NEGRO, LA FERIA DE LOS MILLONES (Completo ), 2013. http:// www.youtube.com/watch?v=B1HIAvXR5ok\&feature=youtube_gdata_player. 
González, F., Gutiérrez, O., Nieto, C., Aponte, A., \& Rodríguez, J. (2012). Conflicto y Territorio en el Oriente Colombiano. Bogotá: Odecofi-Cinep.

Gutiérrez, H., \& Muñoz, D. (2002). Monografia, Manual Especifico de Funciones y Requisitos y Manual de Procedimientos. Puerto Gatian: ESAP Territorial Meta.

Jimenez Benítez, W. (2005). Cdim ESAP. Recuperado el 14 de Noviembre de 2013, de http://cdim. esap.edu.co/BancoMedios/Documentos\%20PDF/reforma $\% 20$ administrativa $\% 20 \mathrm{y} \% 20$ carrera $\% 20$ administrativa $\% 20$ en $\% 20$ colombia.pdf

Longo, Francisco, Iacoviello, Mercedes, Hacia un empleo público más profesional en Centroamérica. Administración y Desarrollo, 2013, 3-30

Martinez Cardenas, E. E. (2010). La carrera Administrativa en Colombia, 70 años de ficcion. $R e-$ dalyc, 107- 125.

Martinez Cardenas, E. E., \& Ramirez Mora, J. M. (2012: Pag 48). La Ficcion de La Carrera Administrativa en Colombia. Bogat D.C: ESAP: Imprenta Nacional.

Puentes González, G. (2004). Carrera Administrativa y Democracia. Administracion \& Desarrollo, 52- 53.

Puerto Gaitán. (s.f.). Recuperado el 24 de 10 de 2013-a, de Alcaldia Municipal de Puerto Gaitan: http://www.puertogaitan-meta.gov.co/dependencias.shtml?apc=dbxx-1-\&x=1502793

Puerto Gaitán. (1998-a). Progreso y Desarrollo con Honestidad. 1998-2000. Puerto Gaitan Meta.

Puerto Gaitán. (2001-a). Decreto 082, por e se cual se adopta la estructura de la Planta de personal. Puerto Gaitan.

Puerto Gaitán. (2001-b). Plan de Desarrollo, 2001-2003. Puerto Gaitan Meta.

Puerto Gaitán. (2004-a). Ejecuciones Presupuestales, Ingresos 2004. Villavicencio.

Puerto Gaitán. (2004-b). Ejecuciones Presupuestales, Gastos 2004. Puerto Gaitán.

Puerto Gaitán. (2004-c). Plan de desarrollo con nuestra gente gobernamos, 2004-2007. Puerto Gai$\tan$ Meta.

Puerto Gaitán. (2005-a). Ejecuciones Presupuestales, Ingresos 2005. Puerto Gaitán.

Puerto Gaitán. (2005-b). Ejecuciones Presupuestales, Gastos 2005. Puerto Gaitán.

Puerto Gaitán. (2005-c). Decreto 108, por el cual se ajusta el manual especifico de funciones y competencias laborales para los empleos de la planta de personal. Decreto 108, por el cual se ajusta el manual especifico de funciones y competencias laborales para los empleos de la planta de personal. Puerto Gaitán, Meta, Colombia.

Puerto Gaitán. (2008- b). Plan de desarrollo capacidad para el desarrollo, 2008-2011. Puerto Gaitan Meta. 
Puerto Gaitán. (2008-a). Manual de funciones y competencias laborales, programa de ajuste y modernizacion institucional. Puerto Gaitan Meta.

Puerto Gaitán. (2008-b). Decreto 193, por el cual se establece la estructura organica de la administracion central. Puerto Gaitan Meta.

Puerto Gaitán. (2013). Entidades descentralizadas, Vicariato Apostolico. Recuperado el 27 de 12 de 2013, de http://www.puertogaitan-meta.gov.co/Entidades_descentralizadas.shtml?apc=1bxx-1$\& x=2355321$

Ramírez, W., Garzón, J., Kalyvas, S., Arjona, A., Cuéllar, F., \& Cubides, F. (2005). El Poder Paramilitar. Colombia: Planeta Colombia S.A.

Registraduría Nacional del Estado Civil. (2000-a). Reginal 2000. Colombia.

Registraduría Nacional del Estado Civil. (2003-a). Reginal 2003. Colombia.

Registraduría Nacional del Estado Civil. (2006-a). Estadisticas Electorales 2006. Colombia.

Registraduría Nacional del Estado Civil. (28 de Octubre de 2007-a). Estadisitca Elecciones 28 de Octubre de 2007. Colombia.

Registraduría Nacional del Estado Civil. (30 de Octubre de 2011-a). Estadisticas Convoto 2011. Colombia.

Romero, M. (2011). La economía de los Paramilitares. Bogotá: Corporación Nuevo Arco Iris.

Saavedra Echeverry, S. (2012). Evolucion e institucionalizacion de la burocracia profesional en el municipio de Cali (administracion central 2001- 2010. Administracion \& Desarrollo, 42- 49.

Velásquez, F., Zuluaga, J., Valencia, L., Cubides, F., Gonzalez, E., Rodríguez, C., y otros. (2009). Las Otras Caras del Poder, Territorio, conflicto y gestión pública en municipios colombianos. Bogotá: Fundación Foro Nacional por Colombia.

Vivas C, O., Younes M, D., Peña B, J., \& Torres V , J. (2012). Anatomia de la Cooptación en Colombia. Bogota D.c: Imprenta Nacional de Colombia .

Zuluaga, O. I. (2004). Ley de Carrera Administrativa. Administracion \& Desarrollo, 117. 